\title{
Caracterização de Efluente Anaeróbio
}

\section{Pâmela A. Sachetto*, Luana M.O.Cruz.}

\section{Resumo}

O objetivo deste trabalho é caracterizar o efluente anaeróbio da Estação de Tratamento de Esgoto (ETE) de Barão Geraldo, que será utilizado para alimentar um reator de bancada operado para remoção de nitrogênio via processo Anammox, quanto a composição de matéria orgânica nos diferentes dias e horários da semana, assim como verificar a influência da sazonalidade e prever o comportamento da bactéria em frente ao uso deste efluente na operação do reator. Para isso foram realizadas análises de turbidez, condutividade, $\mathrm{pH}$, alcalinidade total e parcial, Demanda Química de Oxigênio (DQO) total e solúvel, nitrogênio amoniacal, nitrito, nitrato, nitrogênio total kjeldahl (NTK) e fósforo em amostras simples e compostas de diferentes dias e horários da semana. Os resultados obtidos mostraram que a maioria dos parâmetros do efluente estudado se encontram dentro do esperado pela literatura e a razão $D Q O / N$ foi de 2,5, razão esta favorável a remoção de nitrogênio via processo anammox.

\section{Palavras-chave:}

Anammox, matéria orgânica, influência.

\section{Introdução}

O processo anammox tem sido amplamente estudado. Entretanto, a maioria dos estudos acerca deste processo são desenvolvidos em reatores alimentados com esgoto sintético. Deste modo, se faz necessária a verificação da atividade destas bactérias em condições reais com esgoto doméstico. Neste contexto, o presente projeto tem como objetivo estudar e caracterizar detalhadamente o efluente anaeróbio que será empregado em um reator operado em escala de laboratório com bactérias anammox. Sua composição em termos de concentração de material orgânico dissolvido ou suspenso foi descrita para inferir quais os possíveis interferentes. Espera-se obter dados importantes para planejamento de sua operação e qual a influência da composição do esgoto na atividade anammox.

\section{Resultados e Discussão}

Realizou-se análises de amostras compostas do efluente anaeróbio em triplicata de três dias da semana e com isso se obteve a caracterização média do efluente para cada estação do ano, conforme apresentado na tabela 1.

Pode-se observar que a maioria dos dados experimentais está dentro ou próximo da faixa encontrada na literatura. No entanto, a DQO das amostras do verão apresentaram valores muito inferiores ao esperado (DQO total esperada: $173^{1} \mathrm{mg} \mathrm{O} / \mathrm{L}$ ), o que pode ser explicado pelo fato da amostra ser analisada no dia seguinte da coleta e neste meio tempo ocorrer sua degradação. Já as amostras do outono, foram preservadas com ácido, o que impede sua degradação e com isso obteve-se valores de DQO total próximo ao valor esperado. Os sólidos suspensos totais e voláteis, também apresentaram valores inferiores ao esperado. Além disso, pode-se observar que a maioria dos parâmetros, exceto condutividade e DQO solúvel, apresentaram maiores valores no outono do que no verão, o que pode ser justificado pelo fato de no verão ter tido mais chuva e, portanto, o efluente estaria mais diluído, apresentando menores valores dos parâmetros avaliados. A razão $\mathrm{DQO} / \mathrm{N}$ é extremamente importante para a operação do reator, pois é ela que controla o equilíbrio entre bactérias heterotróficas, $\mathrm{AOB}, \mathrm{NOB}$ e bactérias anammox ${ }^{2}$. O efluente estudado apresentou razão DQO/N média de 2,5 \pm 0,3 que está dentro do intervalo entre 1,7 e 3 , onde o processo anammox é favorecido ${ }^{3} 4$.

Tabela 1. Média das amostras compostas

\begin{tabular}{|c|c|c|}
\hline Parâmetro & Verão & Outono \\
\hline Turbidez (NTU) & $57,07 \pm 4,59$ & $118,69 \pm 39,12$ \\
\hline $\mathrm{pH}$ & $6,76 \pm 0,07$ & $7,05 \pm 0,06$ \\
\hline Condutividade (uS) & $535,33 \pm 53,91$ & $410,17 \pm 22,98$ \\
\hline $\begin{array}{c}\text { Alcalinidade Parcial } \\
(\mathrm{mg} / \mathrm{L})\end{array}$ & $143,12 \pm 14,71$ & $211,83 \pm 2,71$ \\
\hline Alcalinidade Total $(\mathrm{mg} / \mathrm{L})$ & $191,04 \pm 5,50$ & $281,26 \pm 3,53$ \\
\hline DQO Total $\left(\mathrm{mg} \mathrm{O}_{2} / \mathrm{L}\right)$ & $70,22 \pm 13,43$ & $157,11 \pm 16,51$ \\
\hline DQO Solúvel $(\mathrm{mg} \mathrm{O} / \mathrm{L})$ & $38,00 \pm 17,63$ & $24,00 \pm 19,47$ \\
\hline Fósforo $(\mathrm{mg} / \mathrm{L})$ & $3,38 \pm 0,07$ & $4,00 \pm 0,27$ \\
\hline SST $(\mathrm{mg} / \mathrm{L})$ & $27,77 \pm 3,72$ & $84,96 \pm 42,27$ \\
\hline SSF $(\mathrm{mg} / \mathrm{L})$ & $3,54 \pm 2,44$ & $16,74 \pm 7,76$ \\
\hline SSV $(\mathrm{mg} / \mathrm{L})$ & $24,23 \pm 3,71$ & $68,22 \pm 34,51$ \\
\hline NH ${ }_{3}(\mathrm{mg} \mathrm{N} / \mathrm{L})$ & $25,32 \pm 1,34$ & $49,75 \pm 1,37$ \\
\hline Nitrito $(\mu \mathrm{m} / \mathrm{L})$ & $4,44 \pm 2,14$ & $8,22 \pm 2,55$ \\
\hline Nitrato $(\mathrm{mg} / \mathrm{L})$ & $0,01 \pm 0,02$ & $0,13 \pm 0,12$ \\
\hline $\mathrm{NTK}(\mathrm{mg} \mathrm{N} / \mathrm{L})$ & $32,16 \pm 2,90$ & $56,07 \pm 0,72$ \\
\hline
\end{tabular}

\section{Conclusões}

O efluente anaeróbio da ETE Barão Geraldo apresentou a maioria dos parâmetros compatíveis com a literatura, apenas a DQO solúvel e os sólidos suspensos totais e voláteis do verão apresentaram valores inferiores. Todos os parâmetros, exceto a condutividade e a DQO, apresentaram maiores valores no outono do que no verão. $\mathrm{E} O$ efluente apresentou razão $\mathrm{DQO} / \mathrm{N}$ de 2,5, razão esta favorável ao processo anammox.

\footnotetext{
1 Saliba P.D.; Sperling, M. V. Performance evaluation of a large sewage treatment plant in Brazil, consisting of na upflow anaerobic sludge blanket reactor followed by activated sludge. Water Science \& Technology, 20032014. 2017.

${ }^{2}$ Meng, J.; Li, J.; Li,J.; Astals, S.; Nan, J.; Deng, K.; Antwi, P.; Xu, P. The role of $\mathrm{COD} / \mathrm{N}$ ratio on the start-up performance and microbial mechanism of AM upflow microaerobic rezctor treating piggery wastewater.Journal of Environmental Management, 825-831. 2018.

3 Lackner, S., Gilbert, E.M., Vlaeminck, S.E., Joss, A., Horn, H., van Loosdrecht, M.C.M., 2014. Full-scale partial nitritation/anammox experiencesean application survey. Water Res. 55, 292 e 303.

${ }^{4}$ Ni, S.Q., Ni, J.Y., Hu, D.L., Sung, S.W., 2012. Effect of organic matter on the performance of granular anammox process. Bioresour. Technol. 110, $701 \mathrm{e}$ 705 .
} 